\title{
Estimation of the solubility parameters of model plant surfaces and agrochemicals: a valuable tool for understanding plant surface interactions
}

\author{
Mohamed Khayet ${ }^{1}$ and Victoria Fernández ${ }^{2^{*}}$
}

\author{
* Correspondence: v.fernandez@ \\ upm.es \\ ${ }^{2}$ Genetics and Eco-physiology \\ Research Group, School of Forest \\ Engineering, Technical University of \\ Madrid, Ciudad Universitaria s/n, \\ 28040, Madrid, Spain \\ Full list of author information is \\ available at the end of the article
}

\begin{abstract}
Background: Most aerial plant parts are covered with a hydrophobic lipid-rich cuticle, which is the interface between the plant organs and the surrounding environment. Plant surfaces may have a high degree of hydrophobicity because of the combined effects of surface chemistry and roughness. The physical and chemical complexity of the plant cuticle limits the development of models that explain its internal structure and interactions with surface-applied agrochemicals. In this article we introduce a thermodynamic method for estimating the solubilities of model plant surface constituents and relating them to the effects of agrochemicals.

Results: Following the van Krevelen and Hoftyzer method, we calculated the solubility parameters of three model plant species and eight compounds that differ in hydrophobicity and polarity. In addition, intact tissues were examined by scanning electron microscopy and the surface free energy, polarity, solubility parameter and work of adhesion of each were calculated from contact angle measurements of three liquids with different polarities. By comparing the affinities between plant surface constituents and agrochemicals derived from (a) theoretical calculations and (b) contact angle measurements we were able to distinguish the physical effect of surface roughness from the effect of the chemical nature of the epicuticular waxes. A solubility parameter model for plant surfaces is proposed on the basis of an increasing gradient from the cuticular surface towards the underlying cell wall.

Conclusions: The procedure enabled us to predict the interactions among agrochemicals, plant surfaces, and cuticular and cell wall components, and promises to be a useful tool for improving our understanding of biological surface interactions.
\end{abstract}

Keywords: Agrochemicals, Cuticle, Plant surfaces, Solubility parameter, Waxes

\section{Background}

Plant surfaces play a major role in protection against multiple potential biotic and abiotic stress factors [1]. To adapt to these multiple functions, the plant epidermis has developed various characteristics, including specialised cell types such as trichomes or stomata [2]. Epidermal cells are surrounded by a cell wall, which plays a crucial structural and physiological role in plant development and survival [3].

Differentiation and maintenance of the epidermis are essential for plant growth and survival and require continuous cross-talk between epidermal cells and their immediate environment [2]. Epidermal cells also provide mechanical support by adhering

(c) 2012 Khayet and Fernández; licensee BioMed Central Ltd. This is an Open Access article distributed under the terms of the Creative Commons Attribution License (http://creativecommons.org/licenses/by/2.0), which permits unrestricted use, distribution, and reproduction in any medium, provided the original work is properly cited. 
strongly to each other via a strengthened cell wall, which is usually noticeably thicker on the external surface. In addition to the asymmetrical deposition of cell wall material, epidermal cells secrete a lipid-rich cuticle specifically into the thickened external cell wall matrix [2]. Therefore, the cuticle may be considered a cutinised cell wall, emphasizing the heterogeneous nature of this layer and its interconnection with the cell wall beneath [4]. The main protective role of the cuticle is related to the prevention of uncontrolled exchange of water and gases between the plant and the surrounding environment [5]. The functional relevance of the cuticle to plant growth and survival is evidenced by the significant commitment of epidermal cells to cuticle production [6].

The cuticle is made of a bio-polymer matrix, waxes that are deposited on to (epicuticular) or intruded into (intracuticular) this matrix, and variable amounts of polysaccharides and phenolics $[4,7]$. It is an asymmetric membrane [8] generally comprising three distinct layers from the outer to the inner side of the organ, namely: (i) the epicuticular wax layer, (ii) the "cuticle proper" containing waxes and cutin and/or cutan, and (iii) the "cuticular layer" composed of cutin and/or cutan and a high polysaccharide content [9].

Waxes commonly constitute 20 to $60 \%$ of the cuticle mass and are complex mixtures of straight chain aliphatics [6]. Wax composition and structure can vary among different species, organs, states of development, and environmental and stress conditions during growth $[10,11]$. The mechanisms of epicuticular wax formation and regeneration have been assessed in some studies [12] and it has been proposed that cuticular transpiration is the driving force behind wax movement through the cuticle $[13,14]$.

The cuticle matrix is commonly made of cutin, which is a biopolymer formed by a network of inter-esterified, hydroxyl- and hydroxy-epoxy $\mathrm{C}_{16}$ and/or $\mathrm{C}_{18}$ fatty acids [15]. At least six different types of cuticular ultrastructures have been identified by transmission electron microscopy (TEM) [9], but their relationship to cutin monomer composition remains unclear $[7,16]$. The formation of cutinsomes, which are spherical nanoparticles resulting from the self-assembly of cutin hydroxyacid monomers in a polar environment, has been demonstrated; cutinsomes have been proposed as building units of the bio-polyester cutin [17].

While cutin is depolymerised and solubilised upon saponification, cuticles from some species contain a non-saponifiable and non-extractable polymer known as cutan, which yields a characteristic series of long chain $n$-alkenes and $n$-alkanes upon flash pyrolysis [18]. Cutin has been found to be the only polymer present in the cuticles of many fruits and leaves of Solanaceae and Citrus species [9], while different proportions of cutin and cutan have been determined in cuticular membranes extracted from leaves [18] and fruits such as peppers, apples or peaches $[19,20]$.

Major differences in surface topography have been observed in different species and organs, but three hierarchical levels of structuring may occur in association with: (i) the general shape of epidermal cells, (ii) cuticular folds, and (iii) epicuticular wax crystals [21]. For example, the presence of papillae [22] or trichomes [20] can have a major effect on surface topography and wettability at the microscale level. Also, increased surface roughness and surface hydrophobicity have been reported owing to the occurrence of nano-scale structures provided by epicuticular wax crystals [22,23].

Different degrees of wettability of leaves from various species have been reported by measuring water contact angles (e.g., [21,24-26]). In addition, phyllosphere-related factors such as the deposition of aerosols or microorganisms can lead to plant surface 
heterogeneity [27,28], especially in urban or polluted habitats [29]. However, non-wettable surfaces have been observed to accumulate particles more slowly than wettable ones [30].

Recently Fernández et al. [20] estimated the surface free energy, polarity and work of adhesion of a model pubescent surface and proposed the implementation of membrane science approaches to exploring the physical-chemical properties of plant surfaces. It has been suggested that the cuticle acts as a "solution-diffusion" membrane for the diffusion of some solvents and solutes [31,32]. To analyse the permeability of the plant cuticle to solutes and solvents, both the solubility and diffusivity of the compounds must be taken into consideration. While diffusivity is a kinetic parameter associated with the molecular size of a compound in relation to the structure of the matrix, solubility is a thermodynamic parameter that indicates the affinity of a given chemical for the cuticle. Therefore, and as a preliminary step towards the evaluation of plant cuticle permeability, we have analysed for the first time the solubility of model plant surfaces and chemical constituents in relation to agrochemicals of commercial significance, following a thermodynamic approach. Prediction of solubility parameters is commonly used, for example, in the design and fabrication of polymeric membranes [33,34], in the coating industry [35] and also in pharmacology [36]. However, with the exception of the human skin [37,38], this procedure has not so far been applied to estimating the properties of biological surfaces.

As model plant surfaces, peach and pepper fruits were selected since they contain alkanes as major wax constituents but have significantly different surface topographies. Juvenile Eucalyptus globulus leaves, which are covered with a dense layer of nano-tubes and contain $\beta$-diketones as dominant waxes, were also evaluated for comparison.

For model plant surfaces, cuticular constituents and agrochemicals, the following hypotheses were tested: (i) is it possible to predict the solubility of plant surface constituents and the affinity of agrochemicals for plant surfaces? and (ii) can solubility parameters be used to estimate the properties of the plant cuticle?

\section{Materials and methods}

Plant material

The plant materials analysed correspond to intact, undamaged mature peaches (Prunus persica (L.) Batsch. cv. 'Calrico'), red bell peppers (Capsicum annum L. cv. 'Genil') and juvenile Eucalyptus leaves (Eucalyptus globulus Labill. ssp. globulus).

\section{Epicuticular waxes, cutin monomers and cell wall polysaccharides}

The properties of the major wax constituents present in Eucalyptus leaves, bell peppers and peach fruits were used for calculating the solubility parameters (Figure 1, Table 1). Alkanes are the dominant class of compounds covering the surface of the peach fruits analysed [20]. Alkanes are also the dominant class of wax compounds extracted from pepper fruits, followed by triterpenoids such as $\alpha$ - or $\beta$-amyrin [39-41]. Beta-diketones are the dominant class of wax compounds in juvenile Eucalyptus leaves, but $n$-nonacosane, heptadecan-2-one and $n$-hexacosanal are also present in significant concentrations [42-46].

To estimate the solubility parameter range of the cuticle matrix, calculations were carried out with model cutin monomers, which have commonly been identified in plant cuticle monomer analyses $[47,48]$. The selected $\omega$-hydroxy-fatty acids are: 16 -hydroxy- 


\begin{tabular}{|c|c|c|}
\hline $\mathrm{CH}_{3}-\left(\mathrm{CH}_{2}\right)_{14}-\mathrm{CO}-\mathrm{CH}_{2}-\mathrm{CO}-\left(\mathrm{CH}_{2}\right)_{14}-\mathrm{CH}_{3}$ & $\mathrm{CH}_{3}-\left(\mathrm{CH}_{2}\right)_{29}-\mathrm{CH}_{3}$ & $\mathrm{CH}_{3}-\left(\mathrm{CH}_{2}\right)_{23}-\mathrm{CH}_{3}$ \\
\hline$n$-Tritriacontan-16,18-dione & $n$-Triacontane & $n$-Pentacosane \\
\hline $\begin{array}{l}\mathrm{CH}_{2}-\left(\mathrm{CH}_{2}\right)_{14^{-}} \mathrm{COOH} \\
\text { OH }\end{array}$ & \multicolumn{2}{|c|}{$\begin{array}{l}\mathrm{CH}_{2}-\left(\mathrm{CH}_{2}\right)_{5}-\underset{\mathrm{I}}{\mathrm{CH}}-\left(\mathrm{CH}_{2}\right)_{8}-\mathrm{COOH} \\
\mathrm{OH} \quad \mathrm{OH}\end{array}$} \\
\hline 16-Hydroxy-hexanodecanoic acid & \multicolumn{2}{|c|}{ 10,16-Hydroxy-hexanodecanoic acid } \\
\hline $\begin{array}{ll}\mathrm{C} \\
\mathrm{O} \\
\mathrm{OH}\end{array} \mathrm{H}_{2}-\left(\mathrm{CH}_{2}\right)_{7}-\underset{\mathrm{I}}{\mathrm{CH}}-\mathrm{CH}-\left(\mathrm{CH}_{2}\right)_{7}-\mathrm{COOH}$ & \multicolumn{2}{|c|}{$\begin{array}{lcc}\mathrm{CH}_{2}-\left(\mathrm{CH}_{2}\right)_{5}-\mathrm{CH}-\mathrm{CH}_{2}-\mathrm{CH}_{2}-\underset{l}{\mathrm{CH}}-\left(\mathrm{CH}_{2}\right)_{7}-\mathrm{COOH} \\
\mathrm{OH} & \mathrm{OH} & \mathrm{OH}\end{array}$} \\
\hline 9,10-Epoxy-18-hydroxy-octadecanoic acid & \multicolumn{2}{|c|}{ 9,12,18-Trihydoxy-octadecanoic acid } \\
\hline
\end{tabular}

hexanodecanoic acid, 10,16-dihydroxy-hexanodecanoic acid, 9,10-epoxy-18-hydroxyoctadecanoic acid, and 9,10,18-trihydoxy-octadecanoic acid (Table 1). Maximal and minimal solubility parameter values were estimated per monomer according to the potential formation of ester bonds.

The solubility parameter of cellulose, a biopolymer formed from unbranched, unsubstituted $(1,4)$ - $\beta$-D-glucan chains [3], was evaluated by estimating the properties of the

Table 1 Chemical formula and molar volume of the dominant epicuticular waxes extracted from Eucalyptus leaves, pepper and peach fruits and of common cutin monomers found in plant cuticles

\begin{tabular}{|c|c|c|c|}
\hline Compound & Chemical formula & ChemSpider ID & Molar volume $\left(\mathrm{cm}^{3} \mathrm{~mol}^{-1}\right)$ \\
\hline \multicolumn{4}{|l|}{ Epicuticular waxes } \\
\hline n-Hentriacontan-14, 16-dione & $\mathrm{C}_{31} \mathrm{H}_{60} \mathrm{O}_{2}$ & 390212 & 534.4 \\
\hline n-Tritriacontan-16, 18-dione & $\mathrm{C}_{33} \mathrm{H}_{64} \mathrm{O}_{2}$ & 136445 & 567.4 \\
\hline n-Pentatriacontan-16, 18-dione & $\mathrm{C}_{35} \mathrm{H}_{68} \mathrm{O}_{2}$ & 104279 & 600.5 \\
\hline Heptadecan-2-one & $\mathrm{C}_{17} \mathrm{H}_{34} \mathrm{O}$ & 17031 & 306.3 \\
\hline Hexadecanal & $\mathrm{C}_{16} \mathrm{H}_{32} \mathrm{O}$ & 956 & 290.0 \\
\hline n-Tricosane & $\mathrm{C}_{23} \mathrm{H}_{48}$ & 12017 & 408.1 \\
\hline n-Tetracosane & $\mathrm{C}_{24} \mathrm{H}_{50}$ & 12072 & 426.7 \\
\hline n-Pentacosane & $\mathrm{C}_{25} \mathrm{H}_{52}$ & 11900 & 441.2 \\
\hline n-Hexacosane & $\mathrm{C}_{26} \mathrm{H}_{54}$ & 11901 & 457.1 \\
\hline n-Heptacosane & $\mathrm{C}_{27} \mathrm{H}_{56}$ & 11146 & 474.2 \\
\hline n-Nonacosane & $\mathrm{C}_{29} \mathrm{H}_{60}$ & 11903 & 507.2 \\
\hline n-Hentriacontane & $\mathrm{C}_{31} \mathrm{H}_{64}$ & 11904 & 540.2 \\
\hline a-Amyrin & $\mathrm{C}_{30} \mathrm{H}_{50} \mathrm{O}$ & 65921 & 420.8 \\
\hline \multicolumn{4}{|l|}{ Cutin monomers } \\
\hline 16-Hydroxy-hexanodecanoic acid & $\mathrm{C}_{16} \mathrm{H}_{32} \mathrm{O}_{3}$ & 10034 & 284.8 \\
\hline 10,16-Hydroxy-hexanodecanoic acid & $\mathrm{C}_{16} \mathrm{H}_{32} \mathrm{O}_{4}$ & 390182 & 282.7 \\
\hline 9,10-Epoxy-18-hydroxy-octadecanoic acid & $\mathrm{C}_{18} \mathrm{H}_{34} \mathrm{O}_{4}$ & 7994062 & 309.6 \\
\hline 9,12,18-Trihydoxy-octadecanoic acid & $\mathrm{C}_{18} \mathrm{H}_{36} \mathrm{O}_{5}$ & 4446065 & 313.6 \\
\hline \multicolumn{4}{|l|}{ Cell wall polysaccharide monomers } \\
\hline D Glucose & $\mathrm{C}_{6} \mathrm{H}_{12} \mathrm{O}_{6}$ & 96749 & 115.7 \\
\hline D-Galacturonic acid & $\mathrm{C}_{6} \mathrm{H}_{10} \mathrm{O}_{7}$ & 76444 & 109.9 \\
\hline
\end{tabular}


D-glucose monomer. The solubility parameter range of pectins was assessed by analysing the structure of homogalacturonans based on $\alpha-1-4$ linked, D-galacturonic acid Table 2; [3,49].

\section{Chemicals}

Several compounds with different properties and degrees of complexity were selected for calculation of solubility parameters (Figure 2, Table 2). The densities of urea and sorbitol were obtained from the PubChem Bioassay Database (http://pubchem.ncbi. nlm.nih.gov; identification codes: 1176, 5780 and 311, respectively). The molecular structures of plant protection active ingredients (flutolanil, fenoxycarb, chlorothalonil, formetanate, esfenvalerate and cypermethrin) were obtained from ChemSpider with some modifications (Royal Society of Chemistry, UK). Details of the densities of flutolanil, fenoxycarb and fometanate were collected from the Pesticide Properties Database (University of Hertforshire, UK). The densities of chlorothalonil, esfenvalerate and cypermethirn were derived from the European Union Pesticides Database, while data on Genapol X-80 (8 ethylene oxide (EO) units, 13.4 hydrophile-to-lipophile balance (HLB)) and Triton X-100 (assuming 10 EO units and 14.1 HLB) were obtained from Sigma-Aldrich product data-sheets. The density of Brij 35 (23 EO units, 17.1 HLB) was obtained from ChemSpider. Molecular weights were calculated from the number of atoms, and molar volumes were estimated by dividing the molecular weight by the density (Table 2).

\section{Microscopy}

Gold-sputtered intact Eucalyptus adaxial leaves, peach and pepper fruit surfaces were examined with a Hitachi S-3400 N (Tokyo, Japan) and a Philips XL30 (Eindhoven, The Netherlands) scanning electron microscope (SEM).

For TEM observations of Eucalyptus leaf tissue, approximately $1 \mathrm{~mm}^{2}$ sections were cut with a scalpel and fixed in $2 \%$ paraformaldehyde plus $2 \%$ glutaraldehyde (both from Electron Microscopy Sciences (EMS), Hatfield, USA) for $6 \mathrm{~h}$ in ice-cold phosphate buffer (pH 7.2). Samples were subsequently washed five times in phosphate buffer, kept at $4^{\circ} \mathrm{C}$ overnight, and post-fixed with $1 \%$ osmium tetraoxide (TAAB Laboratories, Berkshire, UK) and $1.5 \%$ potassium ferrocyanide (Sigma-Aldrich, Munich, Germany) in distilled water

Table 2 Characteristics of the chemicals used for estimation of solubility parameters

\begin{tabular}{lcccc}
\hline Compound & Chemical formula & Molar volume $\left(\mathbf{c m}^{\mathbf{3}} \mathbf{~ m o l}^{\mathbf{- 1}}\right)$ & ChemSpider ID & Activity \\
\hline Urea & $\mathrm{CH}_{4} \mathrm{~N}_{2} \mathrm{O}$ & 45.2 & 1143 & Fertiliser \\
Sorbitol & $\mathrm{C}_{6} \mathrm{H}_{14} \mathrm{O}_{6}$ & 113.9 & 5576 & Adjuvant \\
Flutolanil & $\mathrm{C}_{17} \mathrm{H}_{16} \mathrm{~F}_{3} \mathrm{NO}_{2}$ & 224.9 & 43579 & Fungicide \\
Fenoxycarb & $\mathrm{C}_{17} \mathrm{H}_{19} \mathrm{NO}_{4}$ & 244.0 & 46739 & Insecticide \\
Chlorothalonil & $\mathrm{C}_{8} \mathrm{Cl}_{4} \mathrm{~N}_{2}$ & 152.8 & 13861400 & Fungicide \\
Formetanate & $\mathrm{C}_{11} \mathrm{H}_{15} \mathrm{~N}_{3} \mathrm{O}_{2}$ & 187.5 & 28856 & Insecticide \\
Esfenvalerate & $\mathrm{C}_{25} \mathrm{H}_{22} \mathrm{ClNO}_{3}$ & 341.4 & 8517510 & Insecticide \\
a-Cypermethrin & $\mathrm{C}_{22} \mathrm{H}_{19} \mathrm{C}_{12} \mathrm{NO}_{3}$ & 313.0 & 2809 & Insecticide \\
Triton X-100 & $\mathrm{C}_{34} \mathrm{H}_{62} \mathrm{O}_{11}$ & 604.5 & 5388 & Surfactant \\
Brij 35 & $\mathrm{C}_{58} \mathrm{H}_{118} \mathrm{O}_{24}$ & 1130.6 & 2006408 & Surfactant \\
Genapol X-80 & $\mathrm{C}_{29} \mathrm{H}_{59} \mathrm{O}_{9}$ & 552.3 & - & Surfactant \\
\hline
\end{tabular}




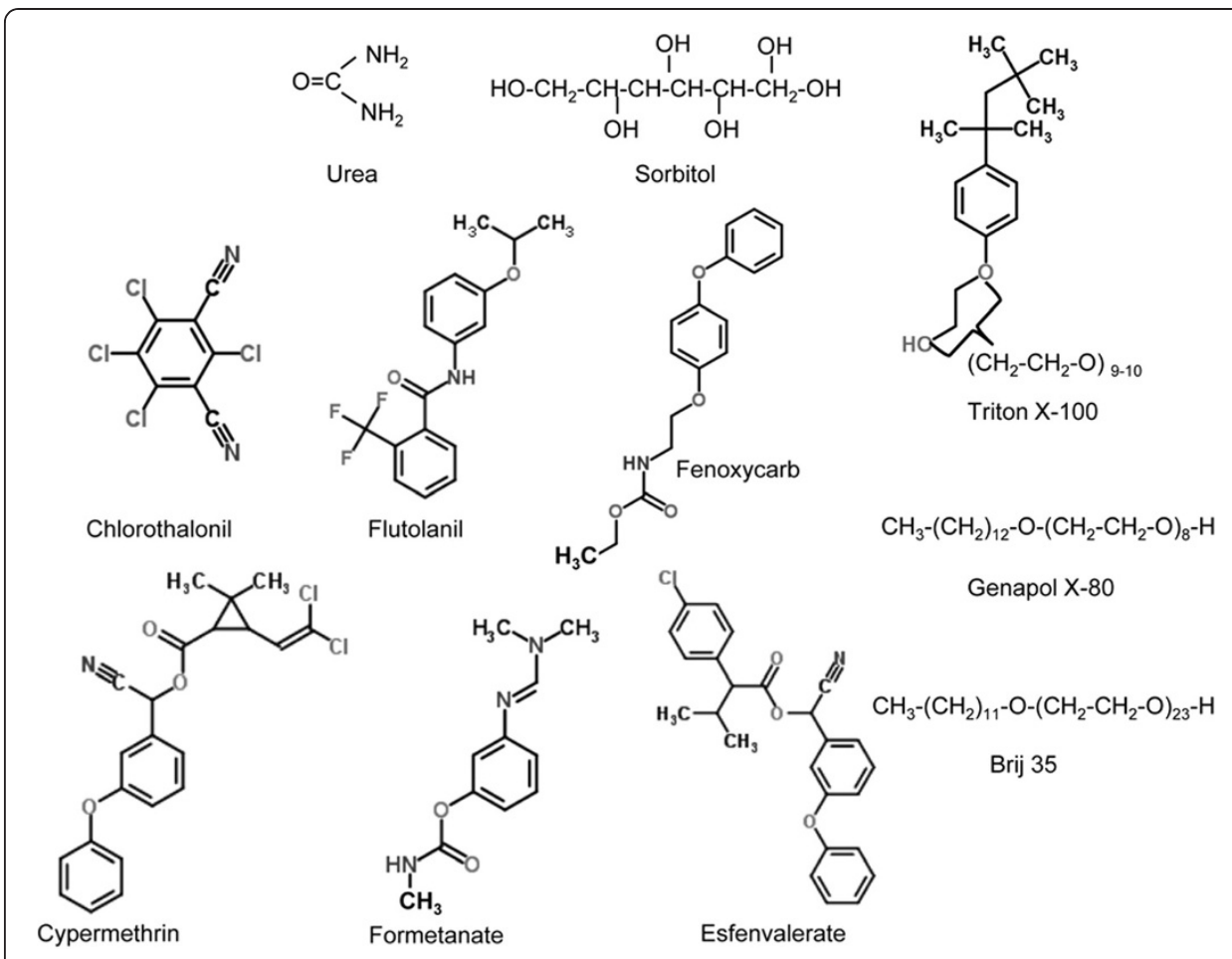

Figure 2 Molecular structures of the agrochemicals selected for calculation of solubility parameters.

$(2 \mathrm{~h})$. They were then rinsed in distilled water $(3 \times 10 \mathrm{~min})$ and dehydrated in an acetone: water $(\mathrm{v} / \mathrm{v})$ series of 50, 60, 70, 80, 90, $95(2 \times 10 \mathrm{~min}$ each $)$ and $100 \%(3 \times 10 \mathrm{~min})$. The tissues were successively immersed in 1:3 (2 h), 1:1 (2 h) and 1:3 (3 h) Spurr's resin:acetone (v/v) solutions and kept overnight in pure Spurr's resin (TAAB Laboratories). The samples were finally placed in moulds and were incubated at $60^{\circ} \mathrm{C}$ for three days. Ultrathin sections were stained with uranyl acetate $(20 \mathrm{~min})$ and lead citrate $(4 \mathrm{~min}$; both chemicals from EMS) and were examined by TEM (Jeol JEM-1010, Tokyo, Japan).

\section{Contact angle measurements and prediction of solubility parameters}

Advancing contact angles of drops of double-distilled water, glycerol and diiodomethane (both $99 \%$ purity, Sigma-Aldrich) were measured at $25^{\circ} \mathrm{C}$ using a CAM 200 contact angle meter (KSV Instruments Ltd., Helsinki, Finland). Contact angles were measured on intact Eucalyptus adaxial leaf, peach and pepper fruit surfaces (30 repetitions). The plant surfaces analysed were collected from fruits and leaves previously observed by SEM. No materials that could affect contact angle measurements (e.g., salt deposits or microorganisms) were found to be deposited on them.

Two $\mu \mathrm{L}$ drops of each liquid were deposited on to the plant surfaces with a manual dosing system holding a $3 \mathrm{~mL}$ syringe $(0.5 \mathrm{~mm}$ diameter needle). Side view images of the drops were captured at a rate of 10 frames $\mathrm{s}^{-1}$. Contact angles were automatically calculated by fitting the captured drop shape to the one calculated from the Young-Laplace equation.

For the three plant surfaces evaluated, the total surface free energy, including its three components (i.e. the Lifshitz-van der Waals (LW), acid (+) and base (-) components), was calculated in addition to the surface polarity and work of adhesion [20]. 


\section{Prediction of solubility parameters}

The solubility parameter of each plant surface analysed, $\delta_{\theta}$, was calculated from the following equation [50]:

$$
\delta_{\theta}=\left(e_{c}\right)^{1 / 2}
$$

where $e_{c}\left(\mathrm{MJ} \mathrm{m}^{-3}\right)$ is the cohesive energy density, which is related to the surface free energy, $\gamma_{s},\left(\mathrm{~mJ} \mathrm{~m}^{-2}\right)$ as follows:

$$
e_{c}=\left(\frac{\gamma_{\mathrm{s}}}{0.75}\right)^{2 / 3}
$$

The solubility parameter of a material can be calculated from either the cohesive energy (Eqn. 1) or the molar attraction constant, $F\left(\left(\mathrm{MJ} / \mathrm{m}^{3}\right)^{1 / 2} \mathrm{~mol}^{-1}\right)$, as:

$$
\delta=\frac{F}{v}
$$

where $v$ is the molar volume $\left(\mathrm{cm}^{3} \mathrm{~mol}^{-1}\right)$ of the molecule [51].

The solubility parameter has three components taking into account the interactions due to dispersion forces $\left(\delta_{d}\right)$, polar forces $\left(\delta_{p}\right)$ and hydrogen $(\mathrm{H})$-bonding $\left(\delta_{h}\right)$, and it is expressed as:

$$
\delta=\sqrt{\delta_{d}^{2}+\delta_{p}^{2}+\delta_{h}^{2}}
$$

According to van Krevelen and Hoftyzer [52], the solubility parameter components can be predicted from group contributions, using the following equations:

$$
\begin{aligned}
& \delta_{d}=\frac{\sum F_{d i}}{v} \\
& \delta_{p}=\frac{\sqrt{\sum F_{p i}^{2}}}{v} \\
& \delta_{h}=\sqrt{\frac{\sum E_{h i}}{v}}
\end{aligned}
$$

where $F_{d i}$ and $F_{p i}$ are the molar attraction constants of the dispersion and polar components, respectively, $E_{h i}$ is the H-bonding energy and $v$ is the molar volume.

The contributions of the functional groups present in the chemicals and plant structural compounds analysed to the solubility parameter components are shown in Table 3. From the solubility parameter components, the total solubility parameter $(\delta)$ can be calculated from Equation 4, and is hereafter named $\delta_{m}$ for agrochemicals, $\delta_{\text {wax }}$ for epicuticular waxes and $\delta_{n m}$ for cutin and polysaccharide monomers.

Finally, to evaluate the affinity of a polymer for a solvent [51] or the affinity of an agrochemical for a given plant surface, the following equation was used:

$$
\Delta \delta_{w a x}=\sqrt{\left(\delta_{m}-\delta_{w a x}\right)^{2}}
$$

Moreover, to study the affinities of the agrochemicals for plant surfaces as derived from the solubility parameter calculated from contact angle measurements $\left(\delta_{\theta}\right)$, the following equation was applied: 
Table 3 Contributions of structural groups present in the selected molecules to the solubility parameter component [52]

\begin{tabular}{|c|c|c|c|}
\hline Structural group & $F_{d i}\left(\left(\mathrm{MJ} / \mathrm{m}^{3}\right)^{1 / 2} \mathrm{~mol}^{-1}\right)$ & $F_{p i}\left(\left(\mathrm{MJ} / \mathrm{m}^{3}\right)^{1 / 2} \mathrm{~mol}^{-1}\right)$ & $E_{h i}(\mathrm{~J} / \mathrm{mol})$ \\
\hline$-\mathrm{CH}_{3}$ & 420 & 0 & 0 \\
\hline$-\mathrm{CH}_{2}^{-}$ & 270 & 0 & 0 \\
\hline$>\mathrm{CH}-$ & 80 & 0 & 0 \\
\hline$=\mathrm{C}<$ & 70 & 0 & 0 \\
\hline$=\mathrm{CH}-$ & 200 & 0 & 0 \\
\hline$>C<$ & -70 & 0 & 0 \\
\hline$<$ & 1430 & 110 & 0 \\
\hline (o, m, p) & 1270 & 110 & 0 \\
\hline$-F$ & 220 & 0 & 0 \\
\hline$-\mathrm{Cl}$ & 450 & 550 & 400 \\
\hline$-\mathrm{OH}$ & 210 & 500 & 20000 \\
\hline$-\mathrm{O}-$ & 100 & 400 & 3000 \\
\hline$-\mathrm{CO}-$ & 290 & 770 & 2000 \\
\hline -COO- & 390 & 490 & 7000 \\
\hline$-\mathrm{COOH}$ & 530 & 420 & 10000 \\
\hline$-\mathrm{COH}$ & 470 & 800 & 4500 \\
\hline$-\mathrm{CN}$ & 430 & 1100 & 2500 \\
\hline$>\mathrm{N}-$ & 20 & 800 & 5000 \\
\hline$-\mathrm{NH}_{2}$ & 280 & 0 & 8400 \\
\hline$-\mathrm{NH}-$ & 160 & 210 & 3100 \\
\hline 1 plane of symmetry & - & $0.50 \times$ & - \\
\hline 2 planes of symmetry & - & $0.25 \times$ & - \\
\hline More planes of symmetry & - & $0 \times$ & $0 \times$ \\
\hline
\end{tabular}

$$
\Delta \delta_{\theta}=\sqrt{\left(\delta_{m}-\delta_{\theta}\right)^{2}}
$$

The results from Equations 8 and 9 imply that the lower the values of $\Delta \delta_{\text {wax }}$ and $\Delta \delta_{\theta}$, the higher the affinity between agrochemical and plant surface.

\section{Results}

\section{Surface topography and hydrophobicity}

The contact angles (in ${ }^{\circ}$ ) of water, glycerol and diiodomethane with plant surfaces are (mean \pm standard deviation): $142.6 \pm 6.7,136.5 \pm 11.2$ and $84.0 \pm 7.0$ for Eucalyptus leaves; 83.4 \pm 4.7, $68.6 \pm 9.2$ and $60.8 \pm 6.2$ for pepper fruits; and $134.2 \pm 7.0,130.9 \pm 7.0$ and $55.7 \pm 3.9$ for peach fruits (see Figure 3 as an illustration of the measurements).

The topographies of the plant materials analysed are shown in Figure 4. The adaxial surface of juvenile Eucalyptus leaves is densely covered with a network of wax nano-tubes, which can be clearly identified as such at higher magnifications (Figure 4D and G). In contrast, the pepper fruit surface is covered with a pattern of epidermal cells (Figure 4B and E) and epicuticular waxes with no clear structure, yielding a smooth and rather flat surface. The peach surface is densely covered with conspicuous trichomes (approximately $1 \mathrm{~mm}$ 

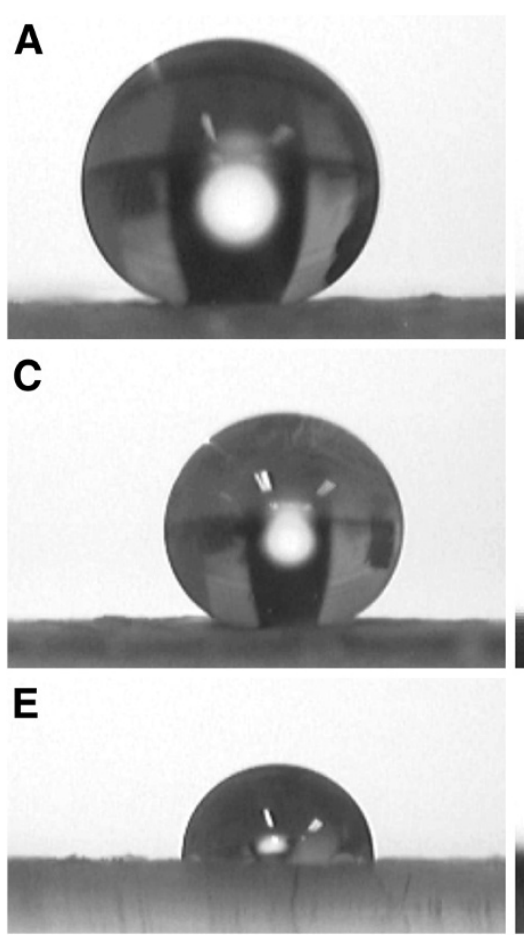

Figure 3 Contact angle measurements on intact, adaxial Eucalyptus $(A, C, E)$ leaf surfaces and pepper fruit surfaces (B,D,F). Drops of: $(\mathbf{A}, \mathbf{B})$ water, $(\mathbf{C}, \mathbf{D})$ glycerol, and $(\mathbf{E}, \mathbf{F})$ diiodomethane.
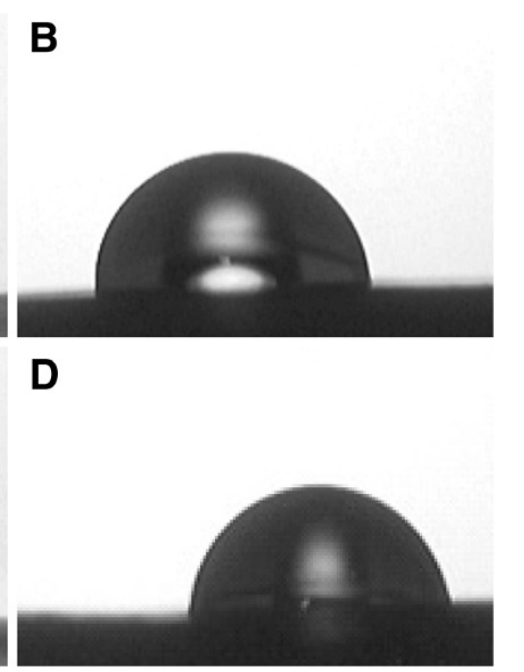

$\mathbf{F}$

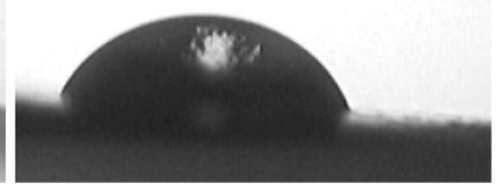

long and $20 \mu \mathrm{m}$ thick), which provide a high degree of micro-scale roughness (Figure 4C, F and I) in contrast to the nano-scale surface roughness of Eucalyptus leaves (Figure 4G). Given the dense and thick network of micro- (trichomes) and nano- (epicuticular waxes) tubes covering peach fruits and Eucalyptus leaves, respectively, we could not determine their roughness by atomic force microscopy.

Adaxial Eucalyptus leaf surfaces are almost super-hydrophobic and the peach fruit surface is also very hydrophobic, while the pepper fruit surface is more wettable.

\section{Surface free energy, polarity, work of adhesion and solubility parameter}

Measurement of contact angles with water, glycerol and diiodomethane enabled several plant surface properties to be calculated (Table 4). The total surface free energies of peach and pepper fruits are similar and significantly higher than that measured for Eucalyptus leaves (approximately 32.2 versus $17.4 \mathrm{~mJ} \mathrm{~m}^{-2}$, respectively). In all cases, there is a major contribution of the Lifshitz-van der Waals component, while the acid-base component is more significant in pepper fruits. Peach and Eucalyptus surfaces have higher contributions from electron acceptor interactions, whilst electron donor interactions predominate in pepper. The lowest and the highest surface polarities correspond to peach and pepper fruits, respectively. The work of adhesion for water and glycerol is much higher in pepper fruits $\left(81.2 \mathrm{~mJ} \mathrm{~m}^{-2}\right)$ than peach fruits and Eucalyptus leaves (between 15.0 and $22.1 \mathrm{~mJ} \mathrm{~m}^{-2}$; Table 4). However, the work of adhesion for diiodomethane lies within a similar range to that for peach and pepper fruits, and is significantly lower in Eucalyptus leaves. 


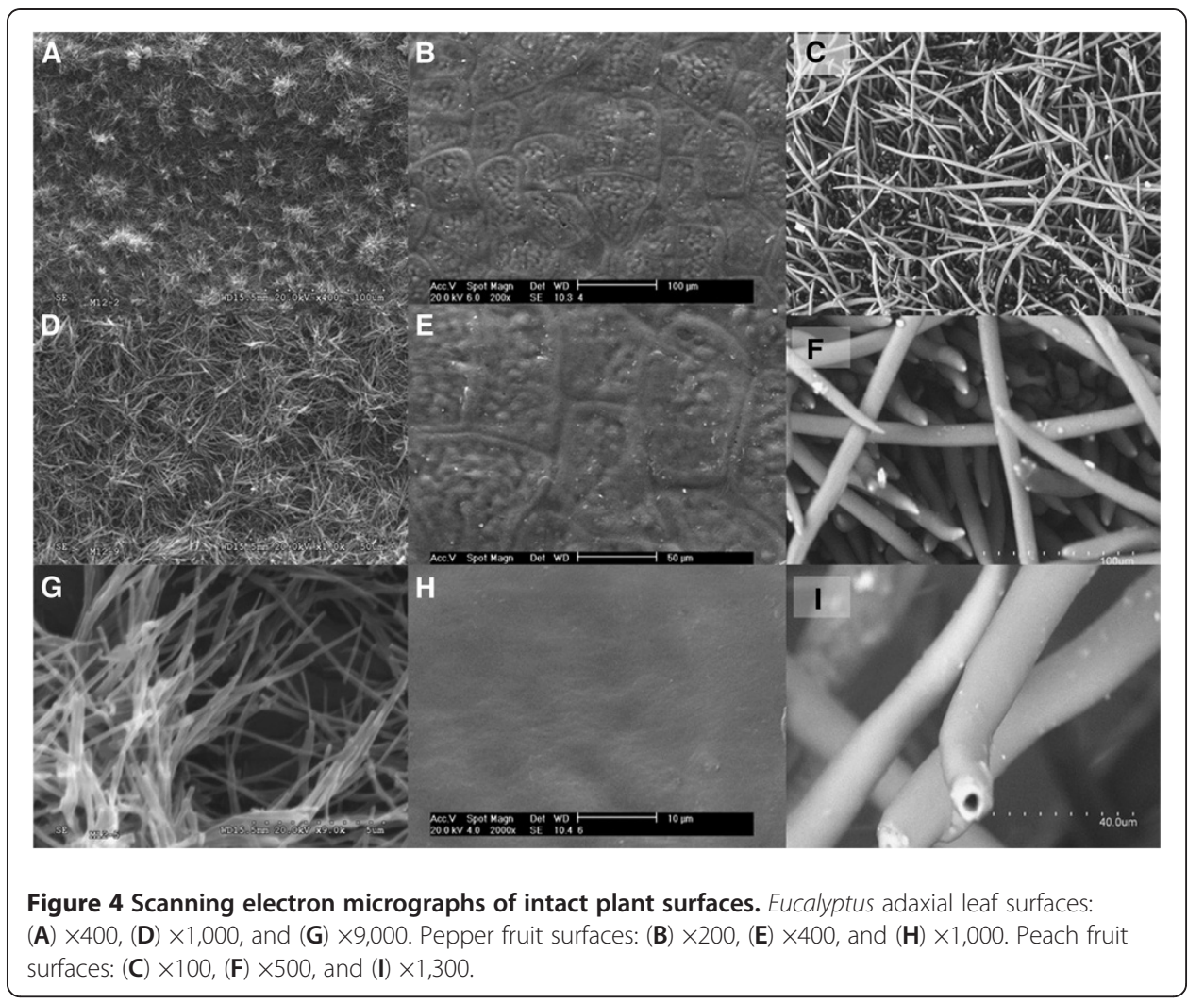

Concerning the solubility parameters $\left(\delta_{\theta}\right)$ of the three plant materials analysed (Table 4), Eucalyptus leaves exhibit a significantly lower value $\left(10.6 \mathrm{MJ}^{1 / 2} \mathrm{~m}^{-3 / 2}\right)$ than pepper and peach fruit surfaces (approximately $17 \mathrm{MJ}^{1 / 2} \mathrm{~m}^{-3 / 2}$ ).

\section{Solubility parameter of epicuticular waxes}

The solubility parameters of the most abundant epicuticular waxes $\left(\delta_{\text {wax }}\right)$ of Eucalyptus leaves, pepper and peach fruits are shown in Table 5.

The dominant class of compounds in both pepper and peach fruit waxes is $n$-alkanes, which have a $\delta_{\text {wax }}$ around $16 \mathrm{MJ}^{1 / 2} \mathrm{~m}^{-3 / 2}$ for the most abundant compounds reported ( $\mathrm{C}_{23}$ to $\mathrm{C}_{31} n$-alkanes). However, it is remarkable that such compounds lack polar $\left(\delta_{p}\right)$ and H-bonding $\left(\delta_{h}\right)$ solubility parameter components. While $n$-alkanes are the most abundant waxes in peach, a relatively abundant class of triterpenoids (e.g., $\alpha, \beta$-amyrin) can be found in pepper fruits. Although the presence of such waxes will not significantly modify $\delta_{\operatorname{wax}}$ $\left(16.7 \mathrm{MJ}^{1 / 2} \mathrm{~m}^{-3 / 2}\right.$, for $\alpha, \beta$-amyrin), they could potentially facilitate interactions due to polar forces and $\mathrm{H}$-bonding owing to the presence of a functional alcohol group.

With regard to Eucalyptus leaves, the dominant class of compounds is $\beta$-diketones, which have a $\delta_{\text {wax }}$ of approximately $16.6 \mathrm{MJ}^{1 / 2} \mathrm{~m}^{-3 / 2}$ and non-zero $\delta_{p}$ and $\delta_{h}$ components owing to the presence of ketone functional groups. Other wax classes often found in $\mathrm{Eu}$ calyptus leaves are $n$-alkanes (chiefly $n$-nonacosane), alkanals (aldehydes) such as hexacosanal, and ketones (e.g., heptadecan-2-one). These kinds of waxes and some others not included in Table 2 (data not shown) were found to have $\delta_{\text {wax }}$ values ranging between 16 and $17 \mathrm{MJ}^{1 / 2} \mathrm{~m}^{-3 / 2}$, but in contrast to $n$-alkanes they all have contributions from $\delta_{p}$ and $\delta_{h}$ because of the presence of aldehyde, ketone and/or alcohol functional groups. 
Table 4 Surface free energy per unit area, Lifshitz van der Waals component $\left(\gamma^{L W}\right)$, acidbase component $\left(\gamma^{A B}\right)$ with the contributions of electron donor $\left(\gamma^{-}\right)$and electron acceptor $\left(\gamma^{+}\right)$interactions, total surface free energy $(\gamma)$, surface polarity $\left(\gamma^{A B} \gamma^{-1}\right)$, solubility parameter $\left(\delta_{\theta}\right)$ and work of adhesion (for water, $W_{w i}$ glycerol, $W_{g}$; diiodomethane, $W_{d}$ ) of adaxial Eucalyptus leaf, pepper and peach fruit surfaces

\begin{tabular}{|c|c|c|c|c|c|c|c|c|c|c|}
\hline \multirow[b]{2}{*}{ Sample } & \multicolumn{7}{|c|}{$\begin{array}{l}\text { Surface free energy and its components } \\
\qquad\left(\mathrm{mJ} \mathrm{m}^{-2}\right)\end{array}$} & \multicolumn{3}{|c|}{$\begin{array}{l}\text { Work of adhesion } \\
\left(\mathrm{mJ} \mathrm{m}^{-2}\right)\end{array}$} \\
\hline & $Y^{L W}$ & $\gamma^{-}$ & $\gamma^{+}$ & $\gamma^{A B}$ & y & $\gamma^{A B} \gamma^{-1}(\%)$ & $\delta_{\theta}\left(M J^{1 / 2} \mathrm{~m}^{-3 / 2}\right)$ & $W_{a . w}$ & $W_{a . g}$ & $W_{\text {a.d }}$ \\
\hline Eucalyptus & 15.5 & 0.2 & 6.5 & 1.0 & 17.4 & 11.2 & 10.6 & 15.0 & 17.6 & 56.1 \\
\hline Pepper & 28.1 & 3.9 & 1.4 & 4.6 & 32.7 & 14.1 & 17.0 & 81.2 & 87.4 & 75.6 \\
\hline Peach & 31.1 & 0.04 & 10.0 & 1.2 & 32.2 & 3.7 & 16.8 & 22.1 & 22.1 & 79.4 \\
\hline
\end{tabular}

For peach and pepper fruits, the values of $\delta_{\theta}$ and $\delta_{\text {wax }}$ are within the same range (16 to $\left.17 \mathrm{MJ}^{1 / 2} \mathrm{~m}^{-3 / 2}\right)$. However, a significantly lower $\delta_{\theta}$ value $\left(10.6 \mathrm{MJ}^{1 / 2} \mathrm{~m}^{-3 / 2}\right)$ was determined for Eucalyptus leaf surfaces than the $\delta_{\text {wax }}$ calculated for $\beta$-diketones (approximately $16.6 \mathrm{MJ}^{1 / 2} \mathrm{~m}^{-3 / 2}$ ). This may be attributed to the nano-structure of the Eucalyptus leaf surface, which decreases the $\delta_{\theta}$ value in association with a high degree of surface roughness and hydrophobicity, as shown for various synthetic and natural materials [53].

\section{Solubility parameters of agrochemicals}

The total solubility parameters $\left(\delta_{m}\right)$ and solubility parameter components of the selected molecules are shown in Table 6 . The water-soluble compounds urea and sorbitol have high $\delta_{m}$ values and major contributions from $\delta_{p}$ and especially $\delta_{h}$. A similarly high $\delta_{m}$ value was determined only for the non-systemic fungicide chlorothalonil, which also has the highest $\delta_{d}$ value of all the compounds considered.

Table 5 Total solubility parameter $\left(\delta_{\text {wax }}\right)$ and solubility parameter components of the most abundant epicuticular waxes of Eucalyptus leaves, pepper and peach fruits

\begin{tabular}{|c|c|c|c|c|}
\hline \multirow{2}{*}{ Compound } & \multicolumn{4}{|c|}{ Solubility parameter components $\left(\mathrm{MJ}^{1 / 2} \mathrm{~m}^{-3 / 2}\right.$ ) } \\
\hline & $\delta_{d}$ & $\delta_{p}$ & $\delta_{h}$ & $\delta_{\text {wax }}\left(M J^{1 / 2} \mathrm{~m}^{-3 / 2}\right)$ \\
\hline \multicolumn{5}{|l|}{ Eucalyptus leaf } \\
\hline$n$-Tritriacontan-16, 18-dione & 16.3 & 1.4 & 2.7 & 16.6 \\
\hline n-Pentatriacontan-16, 18-dione & 16.3 & 1.3 & 2.6 & 16.6 \\
\hline n-Hentriacontan-14, 16-dione & 16.3 & 1.4 & 2.7 & 16.6 \\
\hline n-Nonacosane & 16.0 & 0 & 0 & 16.0 \\
\hline Hexacosanal & 16.2 & 1.8 & 3.1 & 16.0 \\
\hline Heptadecan-2-one & 16.0 & 2.5 & 2.6 & 16.4 \\
\hline \multicolumn{5}{|l|}{ Pepper fruit } \\
\hline$n$-Hentriacontane & 16.1 & 0 & 0 & 16.1 \\
\hline n-Nonacosane & 16.0 & 0 & 0 & 16.0 \\
\hline n-Heptacosane & 16.0 & 0 & 0 & 16.0 \\
\hline$a, \beta$-Amyrin & 15.2 & 2.5 & 2.6 & 16.7 \\
\hline \multicolumn{5}{|l|}{ Peach fruit } \\
\hline n-Pentacosane & 16.0 & 0 & 0 & 16.0 \\
\hline n-Heptacosane & 16.0 & 0 & 0 & 16.0 \\
\hline$n$-Tricosane & 16.0 & 0 & 0 & 16.0 \\
\hline n-Nonacosane & 16.0 & 0 & 0 & 16.0 \\
\hline n-Hexacosane & 16.0 & 0 & 0 & 16.0 \\
\hline n-Tetracosane & 16.0 & 0 & 0 & 16.0 \\
\hline
\end{tabular}


Insecticides (esfenvalerate, fenoxycarb, $\alpha$-cypermethrin and formetanate) and the fungicide flutolanil have $\delta_{m}$ values ranging between 20 to $24 \mathrm{MJ}^{1 / 2} \mathrm{~m}^{-3 / 2}$, with a major contribution from the $\delta_{d}$ component. In contrast, a higher $\delta_{m}$ was determined for the fungicide chlorothalonil. The results also indicate that compounds with different chemical structures such as flutolanil, fenoxycarb and esfenvarelate can have similar $\delta_{m}$ values.

The $\delta_{m}$ values of the three non-ionic surfactants are between 19.5 and $21.4 \mathrm{MJ}^{1 / 2} \mathrm{~m}^{-3 / 2}$ and the differences among them are chiefly associated with the values of the $\delta_{d}$ and $\delta_{p}$ components. The major difference between Genapol X-80 and Brij 35 is related to $\delta_{p}(8.1$ and $5.9 \mathrm{MJ}^{1 / 2} \mathrm{~m}^{-3 / 2}$, respectively). The alkyl-phenol surfactant Triton X-100 lies between the values calculated for the two alkyl ethoxylates $\left(\delta_{m}=20.2 \mathrm{MJ}^{1 / 2} \mathrm{~m}^{-3 / 2}\right)$.

\section{Affinity of agrochemicals for plant surfaces}

Results concerning the affinity of agrochemicals for plant surfaces in relation to $\delta_{\theta}$ and $\delta_{\text {wax }}$ are shown in Figure 5. The affinities of chemicals for the dominant epicuticular waxes present in Eucalyptus leaves, pepper and peach fruits are within a similar range (Figure 5A, $\mathrm{B}$ and $\mathrm{C}$, light grey bars). The $n$-alkanes present in pepper and peach fruit surfaces provide a lower affinity for agrochemicals than the $\beta$-diketones of the Eucalyptus leaf.

The compounds with the lowest affinity for the epicuticular waxes covering the three plant materials analysed (i.e., those with the highest $\Delta \delta_{\text {wax }}$ values) are urea and sorbitol. Regarding the plant protection active ingredients, the highest affinity for epicuticular waxes was calculated for esfenvalerate and flutolanil, followed by fenoxycarb and formetanate. The compounds $\alpha$-cypermethrin and chlorothalonil have higher $\Delta \delta_{\text {wax }}$ values and hence a lower affinity for the dominant waxes. Genapol X-80 is the surfactant with the highest affinity for epicuticular waxes, followed by Triton X-100.

The range of affinities of the agrochemicals for pepper and peach fruit surfaces based on contact angle measurements $\left(\Delta \delta_{\theta}\right)$ is similar to the range predicted from the dominant epicuticular waxes $\left(\Delta \delta_{\text {wax }}\right)$. In contrast, lower affinities of agrochemicals for the Eucalyptus leaf surface were estimated in relation to contact angle measurements, which take into account the combined effects of surface chemistry and roughness (Figure 5, dark grey bars).

Table 6 Total solubility parameters $\left(\delta_{m}\right)$ and solubility parameter components of agrochemicals

\begin{tabular}{lcccc}
\hline \multicolumn{5}{c}{ Solubility parameter components $\left.\mathbf{~ ( M J ~}^{\mathbf{1 / 2}} \mathbf{~ m}^{\mathbf{- 3 / 2}}\right)$} \\
\hline Compound & $\delta_{d}$ & $\delta_{p}$ & $\delta_{h}$ & $\delta_{m}\left(\mathbf{M J}^{\mathbf{1 / 2}} \mathbf{m}^{-3 / 2}\right)$ \\
Urea & 18.8 & 8.5 & 20.4 & 29.0 \\
Sorbitol & 17.3 & 6.1 & 31.3 & 36.3 \\
Flutolanil & 18.8 & 3.8 & 5.8 & 20.0 \\
Fenoxycarb & 19.1 & 4.0 & 6.1 & 20.4 \\
Chlorothalonil & 25.7 & 10.2 & 6.6 & 28.4 \\
Formetanate & 17.7 & 9.0 & 8.4 & 21.6 \\
Esfenvalerate & 18.8 & 2.6 & 6.2 & 20.0 \\
a-Cypermethrin & 22.6 & 4.1 & 6.5 & 23.9 \\
Triton X-100 & 16.7 & 6.7 & 9.1 & 20.2 \\
Brij 35 & 17.7 & 8.2 & 8.9 & 21.4 \\
Genapol X-80 & 16.3 & 5.7 & 8.9 & 19.5 \\
\hline
\end{tabular}




\section{Solubility parameter gradient across the plant surface}

The total solubility parameters $\left(\delta_{m n}\right)$ and solubility parameter components of model cutin monomers and cell wall polysaccharides are shown in Table 7. The values estimated for free $\omega$-hydroxy-fatty acids, D-glucose and D-galacturonic acid are higher than those calculated after monomer esterification or formation of glycosidic bonds, mainly because the $\mathrm{H}$-bonding component is lower.

The $\delta_{m n}$ values of the monomers were estimated by determining the possible minimum and maximum values in association with the potential occurrence of more than two ester bonds (e.g., on 9,10,18-tryhidroxy-octadecanoic acid). The presence of free hydroxyl groups will raise the value of $\delta_{h}$ and hence increase the total solubility parameter. This can be observed, for example, by contrasting 10,16-oxy-hexanodecanoate (three ester bonds) with 10-oxy, 16-hydroxy-hexanodecanoate (two ester bonds); the $\delta_{m n}$ values are 17.9 and $19.4 \mathrm{MJ}^{1 / 2} \mathrm{~m}^{-3 / 2}$, respectively. Similarly, the monomer 9,12,18-oxyoctadecanoate (four ester bonds; $17.7 \mathrm{MJ}^{1 / 2} \mathrm{~m}^{-3 / 2}$ ) has a lower $\delta_{m n}$ value than 9-oxy,
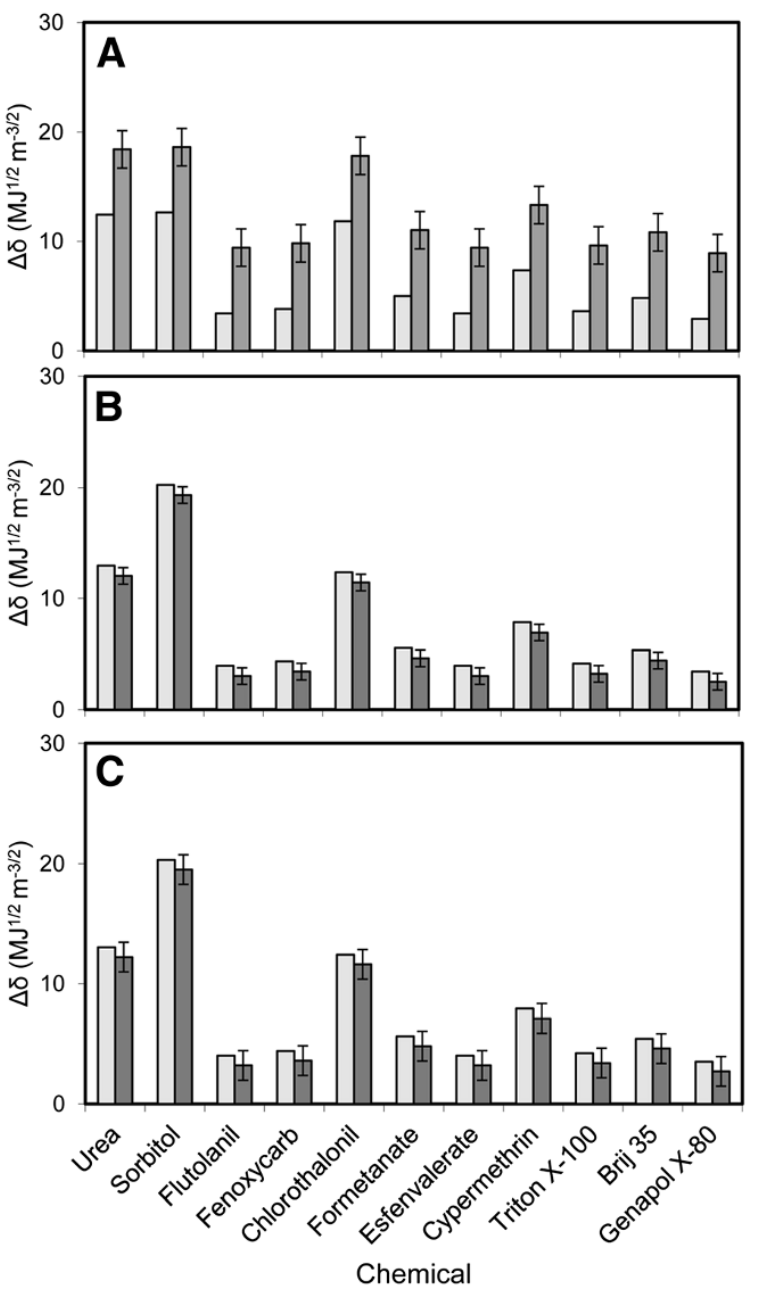

Figure 5 Affinity of agrochemicals for Eucalyptus leaf (A), pepper (B) and peach fruit (C) surfaces. Light grey bars represent the calculated $\Delta \delta_{\text {wax }}$ based on the solubility of agrochemicals in relation to the most abundant epicuticular wax compound $\left(\delta_{\text {wax }}\right)$, and dark grey bars refer to $\Delta \delta_{\theta}$ ( \pm standard errors), calculated from contact angle measurements $\left(\delta_{\theta}\right)$. 
18,12-dihydroxy-octadecanoate (two ester bonds; $20.0 \mathrm{M}^{1 / 2} \mathrm{~m}^{-3 / 2}$ ). The cutin monomers derived from 16-hydroxy-hexanodecanoic and 9,10-epoxy-18-hydroxy-octadecanoic acid can only form two ester bonds and have the lowest $\delta_{m n}$ parameter.

The total solubility parameters determined for polymerised D-glucose and Dgalacturonic acid (around $32.2 \mathrm{MJ}^{1 / 2} \mathrm{~m}^{-3 / 2}$ ) are remarkably above the range assessed for waxes and cutin, chiefly because of the major contributions of the $\delta_{p}$ and $\delta_{h}$ components. Methylation of the carboxylic group in the pectic compound leads to only a slight increase of the $\delta_{m n}$ parameter (data not shown).

By analysing the solubility parameter results estimated for the different materials covering epidermal cells and for the dominant epicuticular waxes present in the three species used for contact angle determinations, a solubility parameter gradient from the outer to the inner side of the cuticle can be expected as depicted in Figure 6. The epicuticular wax layer, which is in direct contact with the atmosphere, has the lowest solubility parameter value and may often lack polar and H-bonding components, as observed for $n$-alkanes. Cutin monomers usually form the cuticular matrix and their degree of polymerization can alter the total solubility parameter of the biopolymer (ranging between 17 and $20 \mathrm{MJ}^{1 / 2} \mathrm{~m}^{-3 / 2}$ ). In the more external cuticular layers there are variable proportions of waxes and cutin (i.e., in the epicuticular wax layer and cuticle proper). Polysaccharides are present in the cuticular layer in direct contact with the cell wall. Therefore, according to current views on the composition of the materials (cuticle and cell wall) covering epidermal plant cells, a solubility parameter gradient is established from the external and more hydrophobic epicuticular wax layer towards the more hydrophilic internal cell wall.

\section{Discussion}

In this study, a procedure for predicting the interactions among different structural plant surface constituents and agrochemicals, based on the estimation of solubility parameters, has been introduced for the first time in a plant science context. While prediction of solubility parameters is commonly used in membrane science [33] and also in pharmacology [36], this procedure has not so far been applied to estimating the

Table 7 Total solubility parameters $\left(\delta_{m n}\right)$ and solubility parameter components of common cutin monomers and cell wall constituents

\begin{tabular}{|c|c|c|c|c|}
\hline \multicolumn{5}{|c|}{ Solubility parameter components $\left(\mathrm{MJ}^{1 / 2} \mathrm{~m}^{-3 / 2}\right)$} \\
\hline Compound & $\delta_{d}$ & $\delta_{p}$ & $\delta_{h}$ & $\delta_{m n}\left(\mathrm{MJ}^{1 / 2} \mathrm{~m}^{-3 / 2}\right)$ \\
\hline \multicolumn{5}{|c|}{ Solubility parameter range of cutin monomers (minimal and maximal values) } \\
\hline 16-Oxy, hexanodecanoate & 15.9 & 2.2 & 5.9 & 17.2 \\
\hline 9,10-Epoxy-18-oxy-octadecanoate & 15.5 & 3.0 & 6.5 & 17.1 \\
\hline 10,16-Oxy- hexanodecanoate & 15.7 & 3.3 & 7.8 & $17.8^{*}$ \\
\hline 10-Oxy, 16-hydroxy-hexanodecanoate & 16.1 & 2.9 & 10.3 & $19.4^{* *}$ \\
\hline $9,12,18,-O x y-o c t a d e c a n o a t e^{*}$ & 15.6 & 4.1 & 7.1 & $17.7^{*}$ \\
\hline 9-Oxy, 18,12-dihydroxy-octadecanoate & 16.3 & 3.8 & 10.9 & $20.0^{* *}$ \\
\hline \multicolumn{5}{|c|}{ Solubility parameter range of cell wall polysaccharide monomers ${ }^{* * *}$} \\
\hline D-Glucose & 13.8 & 16.6 & 24.2 & 32.6 \\
\hline D-Polygalacturonic acid & 15.0 & 14.7 & 23.3 & 31.3 \\
\hline
\end{tabular}

${ }^{*}$ minimal $\delta_{m n}$ assuming that all hydroxyl groups are esterified.

${ }^{* *}$ maximal $\delta_{m n}$ assuming only two ester bonds.

***assuming two glycosidic bonds. 
surface properties of biological materials, with the exception of a few studies focused on human skin $[37,38]$.

The permeability of a compound through a plant cuticle is the product of its solubility, which is a thermodynamic parameter reflecting the degree of interaction between that compound and the plant cuticle, and its diffusivity through the matrix of the plant cuticle, which is a kinetic parameter associated with the molecular size of the compound and the structure of the matrix. This study is only focused on analysing for the first time the solubilities (not the permeabilities) of model plant surfaces and chemical constituents in relation to agrochemicals of commercial significance, adopting a thermodynamic perspective.

Two different approaches have been followed to assess the solubility parameters of plant surfaces. One is based on contact angle measurements $\left(\delta_{\theta}\right)$, which reflect both physical

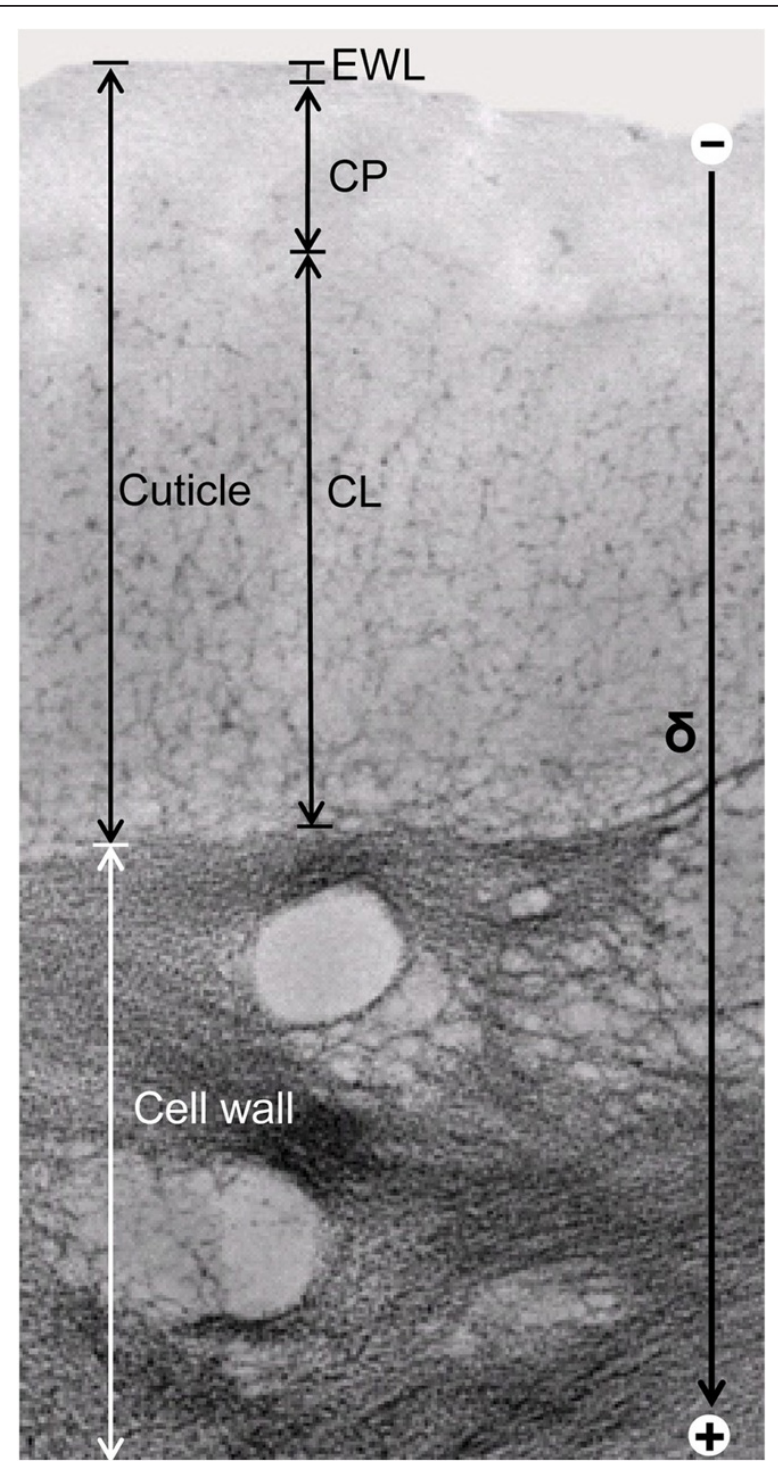

Figure 6 Solubility parameter gradient model for the cuticle and cell wall covering the epidermis of plants. The three cuticular layers are indicated as: EWL (epicuticular wax layer), CP (cuticle proper) and CL (cuticular layer). From the EWL (-) to the cell wall (+) there is a gradual solubility parameter increase. The TEM micrograph corresponds to a transverse section of a juvenile, adaxial Eucalyptus globulus leaf surface $(\times 80,000)$. 
and chemical effects associated with the topography and composition of the surface. The other is limited to considering the nature of the dominant epicuticular waxes covering the surface $\left(\delta_{\text {wax }}\right)$. The three materials selected are good examples of the diversity of plant surface structures in relation to the variability of cell shapes and micro- and nano-structures on the cell surfaces. In addition, the similar chemical composition of the dominant waxes in pepper and peach fruits in contrast to the $\beta$-diketones prevailing in juvenile Eucalyptus leaves offers another interesting aspect to evaluate in the plant surfaces investigated. From an agrochemical viewpoint, substances with different activities, polarities, and degrees of complexity were assessed as model compounds.

\section{Plant surface properties}

The adaxial Eucalyptus leaf surface is almost superhydrophobic and has a high degree of nano-roughness conferred by the dense network of wax nano-tubes [54]. However, the very hydrophobic surface of the highly pubescent peach variety analysed has a high degree of micro-roughness provided by the trichome network. In contrast, the pepper fruit surface has a smooth topography and it is more wettable than the other plant surface samples.

The determination of contact angles of three liquids enabled the three distinct plant materials to be compared by a novel approach [20]. Consequently, the three plant surfaces were characterised in terms of surface free energy, polarity, work of adhesion and solubility parameter. Fruit surfaces have the highest surface free energies and solubility parameter values, in contrast to the Eucalyptus leaf surface. However, the peach skin is the surface with the lowest polarity, which implies the lowest degree of potential polar and $\mathrm{H}$-bonding interactions among the three surfaces analysed. The pepper surface has a significantly higher work of adhesion for water than the peach fruit and the Eucalyptus leaf surface. This indicates that water drops falling on the pepper fruit surface will be retained, in contrast to the repulsion of the drops falling on to peach fruit and especially Eucalyptus leaf surfaces. Therefore, the behaviour of the plant surfaces evaluated may bring some ecophysiological advantage to the plant organs and related species, which future studies should investigate further [20].

Furthermore, the proposed tools based on contact angle measurements of the three liquids may be useful for investigating plant surface dynamics during the growing season or as affected by plant biotic or abiotic stress factors. For example, epicuticular wax erosion in association with environmental pollution [29] or the deposition of aerosols and microorganisms $[27,28]$ could increase the degree of heterogeneity and wettability of the surface, ultimately affecting plant-water relationships [55].

\section{Solubility parameters of cuticular components and agrochemicals}

The solubility parameters of the dominant waxes in the analysed surfaces lie within the range 16.0 to $16.7 \mathrm{MJ}^{1 / 2} \mathrm{~m}^{-3 / 2}$. Such a range is representative of a wide number of wax compounds such as $\beta$-diketones, $n$-alkanes, amyrins, and a few other additional compounds having aldehyde, ketone, and alcohol functional groups. The model cutin monomers evaluated have higher solubility parameters than waxes, varying between 19 and $22 \mathrm{MJ}^{1 / 2} \mathrm{~m}^{-3 / 2}$ for the free $\omega$-hydroxy-fatty-acids and possibly falling to $17 \mathrm{MJ}^{1 / 2} \mathrm{~m}^{-3 / 2}$ after esterification of all functional hydroxyl groups. The model cellulose and pectin monomers have considerably higher solubility parameters than other cuticle constituents, 
which supports previous observations on the hydrophobicity of the cuticle as compared to the cell wall [2].

The presence of wax compounds such as $n$-alkanes renders the plant surface apolar. Despite the smooth topography and wettability of the pepper fruit, its $n$-alkane coating will only lead to the occurrence of dispersive interactions with surface-deposited materials and liquids, a phenomenon that can also be expected for peach fruits.

The different numbers of EO units in the surfactants evaluated had only a slight effect on the total solubility parameter. A correlation between surfactant solubility parameters and HLB or critical micelle concentrations has been reported [56,57]. The surfactant with the lowest solubility parameter (Genapol X-80) was recorded as having the lowest surface tension (approximately $27 \mathrm{~mJ} \mathrm{~m}^{-2}$ at $0.1 \%$ ) while the highest surface tension (around $45 \mathrm{~mJ} \mathrm{~m}^{-2}$ at $0.1 \%$ ) and solubility parameter were estimated for Brij 35 .

It must be noted that water has a total solubility parameter of $47.9 \mathrm{MJ}^{1 / 2} \mathrm{~m}^{-3 / 2}$ [58] and that all chemicals except urea and sorbitol, which can be supplied at concentrations above $1 \%$, were applied at approximately $0.1 \%$ concentrations. However, it can be expected that the chemicals assessed will interact with epicuticular waxes once sprayed on to plant surfaces as aqueous solutions, especially if surface-active agents are applied to improve contact between the solid and the liquid.

\section{Affinities of agrochemicals for plant surfaces}

The affinities of agrochemicals for plant surfaces were evaluated on the basis of contact angle measurements and by considering the chemical structures of the dominant epicuticular waxes. According to Greenhalgh et al. [59], compounds with a solubility parameter difference $(\Delta \delta)$ below $7 \mathrm{MJ}^{1 / 2} \mathrm{~m}^{-3 / 2}$ are likely to be miscible, while chemicals with a $\Delta \delta$ higher than $10 \mathrm{MJ}^{1 / 2} \mathrm{~m}^{-3 / 2}$ are likely to be immiscible. The agrochemicals and plant surfaces selected in this study were found to have $\Delta \delta$ values ranging between $2.5 \mathrm{MJ}^{1 / 2} \mathrm{~m}^{-3 / 2}$ (the highest affinity) and $26.6 \mathrm{MJ}^{1 / 2} \mathrm{~m}^{-3 / 2}$ (no affinity). This indicates that such plant surfaces have a high affinity for some agrochemicals (Genapol X-80, flutolanil, esfenvalerate, Triton X-100, fenoxycarb, Brij 35, formetanate), which can readily penetrate into the plant organ (leaf or fruit in this case), and less affinity for other compounds ( $\alpha$-cypermethrin, sorbitol, urea and chlorothalonil).

The plant protective chemicals with the highest affinities for plant surfaces were found to be those with the lowest total solubility parameters. The high affinities of esfenvalerate, flutolanil and fenoxycarb for the surfaces evaluated make these compounds more prone to cuticular uptake and sorption into plant tissues. Since such plant protection products can be sprayed on to the leaves and fruits of agro-forest species, the estimation of solubility parameters could be used as a complementary tool for pesticide risk assessment. Therefore, the compounds with the lowest toxicity risk will be those with lower affinities for plant surfaces. The proposed methodology may be useful for improving the performance of foliar sprays of e.g., plant protection products, herbicides and fertilisers, taking into account their mode of action (e.g., systemic or contact) and the surface properties of the target organism (e.g., the plant, or surface pathogens and pests).

The surfactants selected in this study also have high affinities for plant surfaces, especially in the case of Genapol X-80. Surfactant solutions sprayed on to foliage have often 
been observed to be phytotoxic [60], which may be associated with the high solubility of some of these compounds in plant surfaces.

The lower affinities of agrochemicals for the Eucalyptus leaf estimated from contact angle measurements are due to the major roughness provided by the wax nano-tubes that densely cover the surface. These nano-tubes are also responsible for the high degree of hydrophobicity of the material [22,23]. In contrast, such differences between the affinities predicted from contact angle measurements and epicuticular wax chemistry were not observed for the peach and pepper fruit surfaces. The micro-scale roughness provided by the dense layer of trichomes covering the peach surface markedly increases the hydrophobicity of that surface, but seems to have limited effect on the solubility parameter.

\section{Solubility parameter gradient model}

To gain insight into the characteristics of the cuticle and the cell wall by calculating solubility parameters, additional estimations were made for common cuticular matrix constituents and cell wall polysaccharides. To our knowledge, this is the first time in which the polar, dispersive and $\mathrm{H}$-bonding properties of plant cuticular and cell wall constituents have been interpreted in quantitative terms. Owing to the properties of the dominant epicuticular waxes present in the three analysed plant materials, it is concluded that the solubility parameter increases with increasing depth from the epicuticular wax surface towards the cell wall. The solubility parameters determined for the model cellulose and pectin compounds are much higher than those for cutin monomers and epicuticular waxes but are still far away from the value of water.

Given the ubiquitous presence of waxes, cutin and polysaccharides in the layers covering plants' epidermal cells [48], and assuming that the chemical constituents selected are representative of a wide range of species with hydrophobic surface properties and within the same range of potential alternative chemical components, a solubility parameter gradient is observed for a model plant surface, which can be applied to e.g., adaxial and abaxial leaf, fruit, flower or trichome surfaces that are covered with a cuticle. On the basis of thermodynamic principles, compounds with a low surface free energy (i.e., a low solubility parameter) will tend to migrate from the plant cell wall towards the epicuticular wax layer in order to decrease the Gibbs free energy [50]. This could be an alternative and/or complementary hypothesis to explain the migration of cuticular material (waxes and cutin) towards the air/plant interface, in contrast to cuticular transpiration as a driving force $[13,14,17]$.

As noted by Scherbatskoy \& Tyree [61], cuticular polymers contain polar and ionisable substituents, providing the cuticle with polar hydrophilic regions and ion exchange capacity. The topography and chemistry of epicuticular waxes generally provide a lower solubility parameter than the one prevailing in the cuticle proper and principally in the cuticular layer, where significant amounts of polysaccharides are present. The lack of polar and H-bonding functional groups in the dominant epicuticular waxes and a higher degree of monomer esterification in the cuticle matrix will tend to lower the total solubility parameter of the membrane by reducing the polar and $\mathrm{H}$-bonding components. The presence of cutan can also decrease the solubility parameter of the cuticle matrix to some extent. According to Jeffree [9], cutanization (i.e., the gradual formation of cutan in the cuticle matrix) of the cuticular layer, as reported for the Clivia minata leaf cuticle [62], can arise from a maturation process involving the progressive modification of the previously deposited cutin and any 
embedded polysaccharides and waxes. The author suggests that the progressive reduction in reactivity of all components of the cuticular layer during cutanisation indicates that all types of polar functional groups are systematically eliminated during this maturation phase.

In order to calculate the solubility parameters, the properties of the trichomes covering the peach skin surface were considered. In this case the cuticular matrix is composed exclusively of cutin, in contrast to the high percentage of cutan in shaved cuticular membranes [20]. According to the cutan hypothesis proposed by Jeffree [9], the cuticular matrix of the peach fruit has a lower solubility parameter than cutin as the dominant cuticular matrix bio-polymer. However, the cuticular domain of the peach fruit cuticle will also have contributions from cutin and polysaccharides, which will gradually raise the total solubility parameter of the membrane as it comes closer to the cell wall. The cuticular matrix of pepper is mainly made of cutin [41], but an insoluble fraction likely to be cutan has also been identified [19]. No information is currently available on the composition of the Eucalyptus globulus leaf cuticle matrix, but the major reduction in solubility parameter associated with the nano-scale roughness of the Eucalyptus surface supports the occurrence of the solubility parameter gradient shown in Figure 6.

While most aerial plant surfaces are believed to be covered with a cuticle based on a cutin and/or cutan matrix, which contains variable amounts of waxes and polysaccharides, trials with more hydrophilic surfaces and different materials should be carried out in the future to estimate the solubility parameters of plant surface chemical constituents quantitatively.

\section{Conclusions}

A novel method for predicting the interactions between plant surface structural constituents, plant surfaces and agrochemicals has been introduced, which was useful for predicting the solubilities of plant surface constituents and the affinities of agrochemicals for plant surfaces. Calculation of the solubility parameters of plant surface constituents led us to observe a solubility parameter gradient established from the cuticular surface towards the wall covering epidermal cells. Comparison of solubility parameters between cuticular and cell wall components will be helpful for clarifying the structure and development of the cuticle from an ontological viewpoint and also for establishing a relationship between the chemical composition and structure of the cuticular membrane, which is currently lacking. The methodology should also be of interest for multiple biological purposes and could help us understand surface phenomena on multiple biological materials.

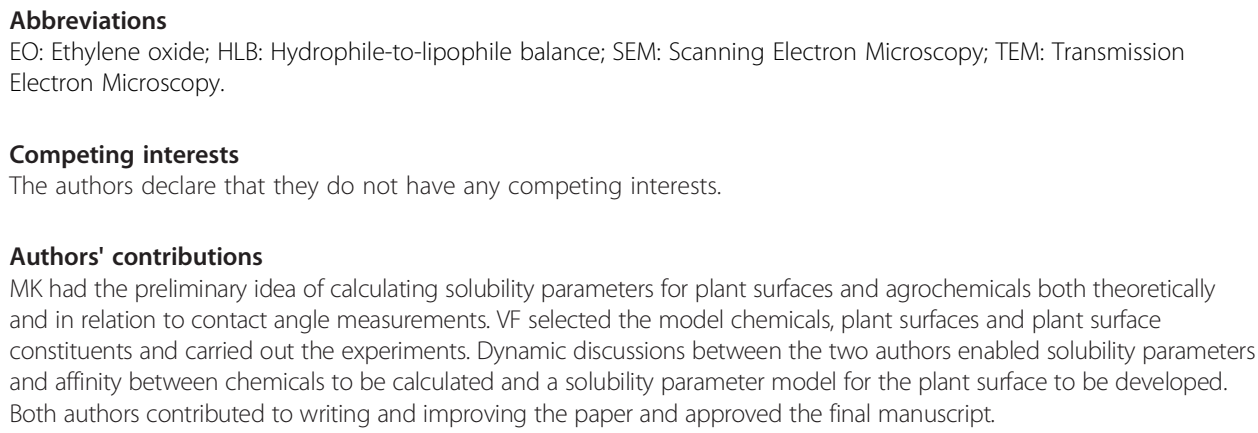


Spain) for technical assistance with TEM. Victoria Fernández is supported by a "Ramón y Cajal" contract (MICINN, Spain), co-financed by the European Social Fund.

\section{Author details}

${ }^{1}$ Department of Applied Physics I, Faculty of Physics, Universidad Complutense, Avda Complutense s/n, 28040, Madrid, Spain. ${ }^{2}$ Genetics and Eco-physiology Research Group, School of Forest Engineering, Technical University of Madrid, Ciudad Universitaria s/n, 28040, Madrid, Spain

Received: 12 September 2012 Accepted: 3 November 2012

Published: 14 November 2012

\section{References}

1. Eichert $T$, Fernández $\mathrm{V}:$ Uptake and release of mineral elements by leaves and other aerial plant parts. In Marschner's Mineral Nutrition of Higher Plants. Edited by Marschner P. San Diego: Academic Press; 2012:71-84.

2. Javelle M, Vernoud V, Rogowsky PM, Gwyneth Cl: Epidermis: the formation and functions of a fundamental plant tissue. New Phytol 2011, 189:17-39.

3. Burton RA, Gidley MJ, Fincher GB: Heterogeneity in the chemistry, structure and function of plant cell walls. Nat Chem Biol 2010, 10:724-732.

4. Domínguez E, Heredia-Guerrero JA, Heredia A: The biophysical design of plant cuticles: an overview. New Phytol 2011, 189:938-949.

5. Fernández V, Eichert T: Uptake of hydrophilic solutes through plant leaves: current state of knowledge and perspectives of foliar fertilization. Crit Rev Plant Sci 2009, 28:36-68.

6. Samuels AL, Kunst L, Jetter R: Sealing plant surfaces: cuticular wax formation by epidermal cells. Ann Rev Plant Biol 2008, 59:683-707.

7. Pollard M, Beisson F, Li Y, Ohlrogge JB: Building lipid barriers: biosynthesis of cutin and suberin. Trends Plant SCi $2008,13: 236-246$

8. Tyree MT, Scherbatskoy T, Tabor CA: Leaf cuticles behave as asymmetric membranes. Evidence from the measurement of diffusion potentials. Plant Physiol 1990, 92:103-109.

9. Jeffree $\mathrm{CH}$ : The fine structure of the plant cuticle. In Annual Plant Reviews, Volume 23. Biology of the Plant Cuticle. Volume 23rd edition. Edited by Riederer M, Müller C. Oxford: Blackwel; 2006:11-125.

10. Kosma DK, Bourdenx B, Bernard A, Parsons EP, Lü S, Joubès J, Jenks MA: The impact of water deficiency on leaf cuticle lipids of Arabidopsis. Plant Physiol 2009, 151:1918-1929.

11. Yeats TH, Buda GJ, Wang Z, Chehanovsky N, Moyle LC, Jetter R, Schaffer AA, Rose JKC: The fruit cuticles of wild tomato species exhibit architectural and chemical diversity, providing a new model for studying the evolution of cuticle function. Plant J 1012, 69:655-666.

12. Jeffree CE, Baker EA, Holloway PJ: Ultrastructure and recrystallization of plant epicuticular waxes. New Phytol 1975, 75:539-549.

13. Neinhuis C, Koch K, Barthlott W: Movement and regeneration of epicuticular wax through plant cuticles. Planta 2001, 213:427-434

14. Koch $K$, Neinhuis C, Ensikat HJ, Barthlott W: Self assembly of epicuticular waxes on living plant surfaces imaged by atomic force microscopy (AFM). J Exp Bot 2004, 55:711-718.

15. Kolattukudy PE: Biopolyester membranes of plants: cutin and suberin. Science 1980, 208:990-1000

16. Graça J, Lamosa P: Linear and branched poly( $\omega$-hydroxyacid) esters in plant cutins. J Agric Food Chem 2010 58(17):9666-9674.

17. Heredia-Guerrero JA, Domínguez E, Luna M, Benítez JJ, Heredia A: Structural characterization of polyhydroxy fatty acid nanoparticles related to plant lipid biopolyesters. Chem Phys Lipids 2010, 163(3):329-333.

18. Villena JF, Domínguez E, Stewart D, Heredia A: Characterization and biosynthesis of non-degradable polymers in plant cuticles. Planta 1999, 208:181-187.

19. Johnson EJ, Chefetz B, Xing B: Spectroscopic characterization of aliphatic moieties in four plant cuticles. Comm Soil Sci Plant Anal 2007, 38:2461-2478.

20. Fernández V, Khayet M, Montero-Prado P, Heredia-Guerrero JA, Liakoloulos G, Karabourniotis G, Del Río V, Domínguez E, Tacchini I, Nerín C, Val J, Heredia A: New insights into the properties of pubescent surfaces: peach fruit as model. Plant Physiol 2011, 156(4):2098-2108.

21. Wagner P, Fürstner R, Barthlott W, Neinhuis C: Quantitative assessment to the structural basis of water repellency in natural and technical surfaces. J Exp Bot 2003, 54:1295-1303.

22. Ensikat HJ, Ditsche-Kuru P, Neinhuis C, Barthlott W: Superhydrophobicity in perfection: the outstanding properties of the lotus leaf. Beilstein I Nanotech 2011, 2:152-161.

23. Bhushan B, Jung YC: Natural and biomimetic artificial surfaces for superhydrophobicity, self- cleaning, low adhesion, and drag reduction. Progress Mater Sci 2010, 56:1-108.

24. Holloway PJ: The effects of superficial wax on leaf wettability. Ann Appl Biol 1969, 63:145-153.

25. Pandey S, Nagar PK: Pattern of leaf surface wetness in some important medicinal and aromatic plants of western Himalaya. Flora 2003, 198:349-357.

26. Aryal B, Neuner G: Leaf wettability decreases along an extreme altitudinal gradient. Oecol 2010, 162:1-9.

27. Burkhardt J: Hygroscopic particles on leaves: nutrients or desiccants? Ecol Monographs 2010, 80:369-399

28. Burkhardt J, Basi S, Pariyar S, Hunsche M: Stomatal penetration by aqueous solutions - an update involving leaf surface particles. New Phytol, In press.

29. Kardel F, Wuyts K, Babanezhad M, Wuytack T, Adriaenssens S, Samson R: Tree leaf wettability as passive bio-indicator of urban habitat quality. Environ Exp Bot 2012, 75:277-285.

30. Neinhuis C, Barthlott W: Seasonal changes of leaf surface contamination in beech, oak, and ginkgo in relation to leaf micromorphology and wettability. New Phytol 1998, 138:91-98.

31. Kerstiens G: Cuticular water permeability and its physiological significance. J Exp Bot 1996, 47:1813-1832. 
32. Riederer M, Friedmann A: Transport of lipophilic non-electrolytes across the cuticle. In Annual Plant Reviews, Volume 23. Biology of the Plant Cuticle. Edited by Riederer M, Müller C. Oxford: Blackwell; 2006:250-279.

33. Khayet M, Suk DE, Narbaitz RM, Santerre JP, Matsuura T: Study on surface modification by surface-modifying macromolecules and its applications in membrane separation processes. J Appl Polym Sci 2003, 89:2902-2916

34. Khayet M, Vazquez Alvarez M, Khulbe KC, Matsuura T: Preferential surface segregation of homopolymer and copolymer blend films. Surface Sci 2007, 601:885-895.

35. Hansen CM: 50 Years with solubility parameters - past and future. Progress Organ Coatings 2004, 51:77-84.

36. Hancock BC, York P, Rowe RC: The use of solubility parameters in pharmaceutical dosage form design. Int J Pharma 1997, 148:1-21.

37. Gröning R, Braun FJ: Three dimensional solubility parameters and their use in characterising the permeation of drugs through the skin. Pharmazie 1996, 51:337-341.

38. Dias M, Hadgraft J, Lane ME: Influence of membrane-solvent-solute interactions on solute permeation in skin. Int J Pharma 2007, 340:65-70.

39. Bauer S, Schulte E, Thier HP: Composition of the surface waxes from bell pepper and eggplant. Eur Food Res Technol 2005, 220:5-10.

40. Kissinger M, Tuvia-Alkalai S, Shalom Y, Fallik E, Elkind Y, Jenks MA, Goodwin MS: Characterization of physiological and biochemical factors associated with postharvest water loss in ripe pepper fruit during storage. J Amer Soc Hort Sci 2005, 130:735-741.

41. Parsons EP, Popopvsky S, Lohrey GT, Lü S, Alkalai-Tuvia S, Perzelan Y, Paran I, Fallik E, Jenks MA: Fruit cuticle lipid composition and fruit postharvest water-loss in an advanced backcross generation of pepper (Capsicum sp.). Physiol Plant 2012, 146(1):15-25.

42. Li H, Madden JL, Potts BM: Variation in leaf waxes of the Tasmanian Eucalyptus species - I. Subgenus Symphyomyrtus. Biochem Systemat Ecol 1997, 25:631-657.

43. Wirthensohn MG, Sedgley M, Jones GP: Epicuticular wax of juvenile Eucalyptus leaves and headspace analysis of leaf volatiles. J Essential Oil Res 2000, 12:401-441.

44. Jones TH, Potts BM, Vaillancourt RE, Davies NW: Genetic resistance of Eucalyptus globulus to autumn gum moth defoliation and the role of cuticular waxes. Canad J Forest Res 2002, 32(11):1961-1969.

45. Rapley L, Allen GR, Potts BM: Susceptibility of Eucalyptus globulus to Mnesampela privata defoliation in relation to a specific foliar wax compound. Chemoecol 2004, 14(3-4):157-163.

46. Steinbauer MJ, Davies NW, Gaertner C, Derridj S: Epicuticular waxes and plant primary metabolites on the surfaces of juvenile Eucalyptus globulus and E. nitens (Myrtaceae) leaves. Aust J Bot 2009, 57:474-485.

47. Kolattukudy PE: Polyesters in higher plants. In Advances in biochemical engineering/ biotechnology. Edited by Scheper T. Berlin: Springer; 2001:4-49.

48. Kolattukudy PE: Cutin from plants. Biopolymers Online. Weinheim: Wiley-VCH Verlag GmbH; 2005.

49. O'Neill MA, York WS: The composition and structure of plant primary cell walls. In The Plant Cell Wall. Edited by Rose JKC. Oxford: Blackwell Publishing/CRC; 2005:1-54.

50. Khayet M, Chowdhury G, Matsuura T: Surface modification of polyvinylidene fluoride pervaporation membranes. AlChE J 2002, 48:2833-2843.

51. van Krevelen DW, te Nijenhuis K: Cohesive properties and solubility. In Properties of Polymers: Their Correlation with Chemical Structure; Their Numerical Estimation and Prediction from Additive Group Contributions. 4th edition. Edited by. Oxford: Elsevier; 2009:189-227.

52. van Krevelen DW, Hoftyzer PJ: Properties of polymers: their estimation and correlation with chemical structure. 2nd edition. Amsterdam: Elsevier; 1976.

53. Nosonovsky M, Bhushan B: Superhydrophobic surfaces and emerging applications: non-adhesion, energy, green engineering. Curr Opin Coll Interf Sci 2009, 14:270-280

54. Wirthensohn MG, Sedgley M: Epicuticular wax structure and regeneration on developing juvenile Eucalyptus leaves. Aust J Bot 1996, 44(6):691-704.

55. Pariyar S, Eichert T, Goldbach HE, Hunsche M, Burkhardt J: The exclusion of ambient aerosols changes the water relations of sunflower (Helianthus annuus) and bean (Vicia faba) plants. Environ Exp Bot, In press.

56. Samaha MW, Naggar VF: Micellar properties of non-ionic surfactants in relation to their solubility parameters. Int J Pharma 1998, 42:1-9.

57. Schott H: Hydrophilic-lipophilic balance, solubility parameter, and oil-water partition coefficient as universal parameters of nonionic surfactants. J Pharma Sci 1995, 84:1215-1222.

58. Senichev VY, Tereshatov W: General principles governing dissolution of materials in solvents. 4.1 Simple solvent characteristics. In Handbook of Solvents. Edited by Wypych G. Toronto: ChemTec; 2001:101-124.

59. Greenhalgh DJ, Williams AC, Timmins P, York P: Solubility parameters as predictors of miscibility in solid dispersions. J Pharma Sci 1999, 88:1182-1190.

60. Uhlig BA, Wissemeier AH: Reduction of non-ionic surfactant phytotoxicity by divalent cations. Crop Prot 2000, 19:13-19.

61. Scherbatskoy T, Tyree MT: Kinetics of exchange of ions between artificial precipitation and maple leaf surfaces. New Phytol 1990, 114:703-712.

62. Riederer M, Schönherr J: Development of plant cuticles fine structure and cutin composition of Clivia miniata Reg. leaves. Planta 1988, 174:127-138.

doi:10.1186/1742-4682-9-45

Cite this article as: Khayet and Fernández: Estimation of the solubility parameters of model plant surfaces and agrochemicals: a valuable tool for understanding plant surface interactions. Theoretical Biology and Medical Modelling 2012 9:45 